\title{
1. Introduction: Innovation and entrepreneurship in sport management
}

\section{Vanessa Ratten}

\section{INTRODUCTION}

Innovation and entrepreneurship are needed in sport in order to deal with uncertainties but also integrate new societal advancements (Andersen \& Ronglan, 2015). The ongoing COVID-19 pandemic has made sport entities change their current market strategies in order to cope with the new normal. The sport industry has been affected by unprecedented changes in terms of social distancing requiring the use of new broadcast technologies and games played with fans. Thus, innovation and entrepreneurship provide a way to deal with change and allow the sport industry to continue (Radaelli, Dell'Era, Frattini \& Petruzzelli, 2018). This is important particularly in the current COVID-19 times in which sport provides a much needed source of entertainment.

Sport entrepreneurship thrives on uncertainty due to the new opportunities it provides (Bjärsholm, 2017). Uncertainty involves the inability to predict certain outcomes in the business environment. This perception results in it being hard to forecast future events due to insufficient information being available. Sport entrepreneurs use this uncertainty to their advantage by providing the necessary products and services (Miragaia, Ferreira \& Ratten, 2017). During times of crisis, levels of uncertainty rise, which can have positive and negative consequences. From a positive view, uncertainty brings opportunities for new sport products to enter the marketplace that cater for specific needs (McSweeney, 2020). Sport entrepreneurs who can cater for these needs are likely to see higher levels of profits (Ratten, 2015). A negative view of uncertainty is due to the shortage in required resources such as finance or capital that are neces- 
sary for sport entrepreneurship. This is particularly concerning for sport entrepreneurs that are reliant on constant streams of revenue or financing for their ventures (Ratten, 2011). Uncertainty is often caused by crises such as natural disasters, political events and financial turmoil. Currently the COVID-19 pandemic has created much global uncertainty due to its unknown length and effect. This is particularly concerning for sport entrepreneurs that are much more international than in the past (Jones, Jones, Williams-Burnett \& Ratten, 2017). In addition, the interdependence of the global economy means that a crisis in one geographic region is likely to have flow-on effects to other areas of the sport ecosystem (Ratten, 2012).

Sport entrepreneurship involves some kind of passion that incorporates intensive positive feelings about the experience (Hemme, Morais, Bowers \& Todd, 2017). This enables sport ventures to be created that are associated with the self-identity of the sport entrepreneur (Bjärsholm, Gerrevell, Linnér, Peterson \& Schenker, 2018). Passion is an essential part of sport entrepreneurship due to the way culture is evident in business ventures. The way passion can be used in sport entrepreneurship differs depending on the context (Ratten, 2018). This means that the emotions and values of a sport entrepreneur tend to be more intense when they are combined with a lifestyle interest. To understand more fully the role of passion in sport entrepreneurship a system view of innovation needs to be considered (Ratten, 2017). Taking a system approach to innovation enables interactive learning to develop.

Sport innovation requires a system approach due to the need to get input from multiple stakeholders. Increasingly sport innovation requires the feedback from different entities in order to gain acceptance in the marketplace (Ratten, 2019). This means rather than being a one-off planned event, sport innovation develops over time based on the collective input of a group of individuals. The interactions of these individuals facilitate a dynamic process that evolves over time. Sport innovations are shaped by the sharing and dissemination of knowledge from multiple sources (Ratten \& Babiak, 2010). The collective sharing of knowledge means the innovations are generated in a new way. This is made possible by the acquisition of dynamic capabilities that cultivates the way knowledge is accessed. This plays an intrinsic role in a sport entrepreneur's ability to be innovative in the marketplace. 


\section{OVERVIEW OF CHAPTERS}

This edited book comprises a number of chapters on a range of topics related to innovation and entrepreneurship in sport. Chapter 2, 'Disruptions in sport management from COVID-19: Lessons from entrepreneurship and innovation' by Vanessa Ratten and Geoff Dickson, focuses on recent developments related to the sport industry. The chapter discusses the way entrepreneurship can be used in times of crisis to help the sport industry. This enables a better understanding of the need to think creatively when there are substantial changes affecting the way sport is viewed and consumed (Cohen \& Peachey, 2015), thereby helping to understand the inherent entrepreneurial nature of sport and how it can be used as a good example of an entrepreneurial industry.

Chapter 3, 'On the importance of tournament design in sports management: Evidence from the UEFA Euro 2020 qualification' by Kjetil K. Haugen and Alex Krumer, focuses on the use of innovation in the UEFA competition. This enables an understanding about the changing nature of tournament designs and how they need to integrate new innovations in order to stay competitive (Hayhurst, 2014). Chapter 4, 'A system innovation related to sports entrepreneurship' by Ben Hattink and Aard Groen, provides a new way to look at entrepreneurship in sport. Due to the variety and diverse nature of stakeholders in sport it is important to take a system view. This helps with analysing the concurrent changes that occur in the sport environment and the effect of these changes on other entities. Chapter 5, 'Technology innovations in sports: Typology, nature, courses and impact' by Ekaterina Glebova and Michel Desbordes, focuses on the role of technology in sport. This is important as many of the new innovations occurring in the sports field are the result of technological advances. Therefore, analysing sport from an innovation perspective will inevitably incorporate a technology view.

Chapter 6, 'Do scientific approaches lead to innovative social entrepreneurial ventures? The relationship between fitness equipment and stages of life' by Silvio Addolorato, Jorge García-Unanue, Leonor Gallardo and Jerónimo García-Fernández, focuses on the non-profit side of sport. This is an important way to understand the different types of entrepreneurship that exist in sport, thereby making an important contribution to the sport management field but also highlighting the impact of fitness clubs on innovation. Chapter 7, 'Sport innovation, entrepreneurship and digital ecosystems' by Esha Thukral and Vanessa Ratten, focuses on the impor- 
tance of digital technology in sport. By taking an ecosystem view it helps to understand the way different sport entities are connected.

Chapter 8, 'Why should we need innovation in sports management?' by Kadir Yıldız, Elvan Deniz Yumuk and Jerónimo García-Fernández, provides an important assessment about why innovation is needed in sport. The chapter critically analyses the innovation perspective in sport by looking at the pros and cons. This helps to understand why more focus should be placed on innovation in sport. Chapter 9, 'COVID-19: Entrepreneurial ecosystem approach to bounce back: Implications for the sport industry' by Esha Thukral and Vanessa Ratten, looks at the way entrepreneurial ecosystems are utilised in sport. This helps to understand the dynamic and interactive nature of the sport industry. The sport industry includes both profit and non-profit entities so it is useful to think about the occurrences in sport from an ecosystem point of view. This enables a better understanding about how different types of sport from amateur, professional, community and hybrid models interact. Chapter 10, 'Coronavirus and sport crisis management: A knowledge spillover perspective' by Vanessa Ratten and Alice Li, focuses on the role of knowledge management in sport, in particular knowledge spillovers, which is a useful way to think about the information that transfers between entities in a sport context.

\section{CONTRIBUTIONS TO CURRENT LITERATURE AND DIRECTIONS FOR FUTURE RESEARCH}

Each of the chapters in this book makes an important contribution to the current literature on innovation and entrepreneurship in sport management. They do this by adding new perspectives on how the sport industry can be innovative or entrepreneurial. This provides thought-provoking ideas about how the sport industry is changing and what needs to be done for it to stay current in the dynamic global business environment. Below, the main contributions of the chapters in the book are discussed in terms of the core themes related to innovation and entrepreneurship. This provides a way to synthesise the current body of knowledge by also making some suggestions about the key takeaways related to each topic.

\section{Individual Innovation and Entrepreneurship}

Each of the chapters views the process of innovation and entrepreneurship in a sport context differently. This makes it important to emphasise 
the individuality and contextual nature of the sport industry, which impacts response to change. Individual innovation can take the role of an instigator, team member, collaborator, supporter or other function depending on the nature of the input. This means it is useful to consider individuals in the process of creating or nurturing sport-related innovation and entrepreneurship. The key takeaways from the chapters related to individual innovation and entrepreneurship are:

- Personal characteristics might affect the response to the COVID-19 crisis and this impacts the rate of sport entrepreneurship in times of crisis.

- Culture influences an individual's propensity for sport entrepreneurship in health pandemics and the flow of knowledge transfer that results.

- Social networks and background influence individual approaches to sport-related entrepreneurship.

\section{Networks}

Networks are an important part of any industry but are much more intrinsic to the sport industry. This is due to the sport industry inciting passion amongst participants in terms of their connections. Current and past athletes often have social networks that enable them to stay connected to a group of individuals. This can help them in future business projects by providing a sense of solidarity. In addition, networks in the sport industry can be related to suppliers or manufacturers of products and services. This enables a system of networks to develop that can help or hinder sport entrepreneurship. The key takeaways related to networks from the chapters include:

- Networks can facilitate or hinder sport-related entrepreneurship and their response approaches.

- The interrelationships amongst sport network members provide knowledge and learning benefits to members.

- There are governance and mechanisms of sport networks during times of crisis with respect to issues such as solidarity and mutual trust.

- Politics and power play a key role in sport networks related to entrepreneurship. 


\section{Firm Level}

At the firm level innovation and entrepreneurship in sport is important for a number of reasons. Most importantly it offers a way for organisations to stay ahead of the competition and to enter new global marketplaces. This provides a useful mechanism to convert ideas into commercial realities thereby paving the way for new revenue streams. Firms in the sport industry include profit and non-profit so it is important to consider both the commercial and social roles that innovation plays. The important takeaways related to a firm-level approach in the chapters include the following:

- The industry context plays an important role on firm-level approaches to sport entrepreneurship. This will help improve our understanding about firm dynamics that shape responses to crises.

- The structure of firms in terms of leadership help in fostering sport-related entrepreneurship initiatives.

- There are firm differences and similarities in developing sport-related entrepreneurship.

\section{Location}

The location of any entrepreneurship or innovation activity in sport needs to be considered. This is due to different societal and political conditions existing in each location. Therefore, location in terms of geography needs to be included in any discussions related to sport entrepreneurship. This will help to understand specific contextual factors that impact how sport changes based on market demand. The key takeaways arising from the chapters included in this book are:

- Location impacts the type of sport-related entrepreneurship as well as how governments influence entrepreneurship.

- Location plays a key role in the success or failure of entrepreneurial activities including the role of connectivity in sport communities.

- Emphasis needs to be placed on sport technological and social conditions of a location in terms of its response mechanisms to change. 


\section{Global}

Sport is becoming increasingly global due to an increased ease of watching and participating in games. This means that taking a global approach is necessary in order to survive in the current market climate. Therefore, the chapters in this book take a global approach to identifying common issues confronting the industry. This helps in assessing the intricate nature of the sport industry and how it needs to be analysed on a global level. Key takeaways from the chapters in the book include:

- There are global or national response mechanisms to innovation and entrepreneurship in sport.

- There has been internationalisation or de-internationalisation as a result of the COVID-19 crisis with regards to sport entrepreneurship.

- There are a number of conditions that impact the internationalisation of response mechanisms via social media to sport innovation.

\section{CONCLUSION}

This chapter provides a useful summary of the way innovation and entrepreneurship are integral to the successful functioning of the sport industry. The chapters in the book were summarised and then key contributions from these chapters discussed, thereby highlighting the unique way sport develops and changes based on societal trends. Due to the ongoing COVID-19 crisis it is becoming more apparent that an innovative and entrepreneurial approach is required for the sustainability of the global sport industry.

\section{REFERENCES}

Andersen, S. S., \& Ronglan, L. T. (2015). Historical paths and policy change: Institutional entrepreneurship in Nordic elite sport systems. International Journal of Sport Policy and Politics, 7(2), 197-216.

Bjärsholm, D. (2017). Sport and social entrepreneurship: A review of a concept in progress. Journal of Sport Management, 31(2), 191-206.

Bjärsholm, D., Gerrevall, P., Linnér, S., Peterson, T., \& Schenker, K. (2018). Ethical considerations in researching sport and social entrepreneurship. European Journal for Sport and Society, 15(3), 216-33.

Cohen, A., \& Peachey, J. W. (2015). The making of a social entrepreneur: From participant to cause champion within a sport-for-development context. Sport Management Review, 18(1), 111-25. 
Hayhurst, L. M. (2014). The 'girl effect' and martial arts: Social entrepreneurship and sport, gender and development in Uganda. Gender, Place and Culture, 21(3), 297-315.

Hemme, F., Morais, D. G., Bowers, M. T., \& Todd, J. S. (2017). Extending sport-based entrepreneurship theory through phenomenological inquiry. Sport Management Review, 20(1), 92-104.

Jones, P., Jones, A., Williams-Burnett, N., \& Ratten, V. (2017). Let's get physical: Stories of entrepreneurial activity from sports coaches/instructors. International Journal of Entrepreneurship and Innovation, 18(4), 219-30.

McSweeney, M. J. (2020). Returning the 'social' to social entrepreneurship: Future possibilities of critically exploring sport for development and peace and social entrepreneurship. International Review for the Sociology of Sport, 55(1), $3-21$.

Miragaia, D. A. M., Ferreira, J. J. D. M., \& Ratten, V. (2017). The strategic involvement of stakeholders in the efficiency of non-profit sport organisations: From a perspective of survival to sustainability. BBR: Brazilian Business Review, 14(1), 42-58.

Radaelli, G., Dell'Era, C., Frattini, F., \& Petruzzelli, A. (2018). Entrepreneurship and human capital in professional sport: A longitudinal analysis of the Italian soccer league. Entrepreneurship Theory and Practice, 42(1), 70-93.

Ratten, V. (2011). Sport-based entrepreneurship: Towards a new theory of entrepreneurship and sport management. International Entrepreneurship and Management Journal, 7(1), 57-69.

Ratten, V. (2012). Guest editor's introduction: Sports entrepreneurship: Towards a conceptualisation. International Journal of Entrepreneurial Venturing, 4(1), $1-17$.

Ratten, V. (2015). Athletes as entrepreneurs: The role of social capital and leadership ability. International Journal of Entrepreneurship and Small Business, 25(4), 442-55.

Ratten, V. (2017). Entrepreneurial sport policy. International Journal of Sport Policy and Politics, 9(4), 641-8.

Ratten, V. (2018). Sport entrepreneurship: Developing and sustaining an entrepreneurial sports culture, Cham: Springer.

Ratten, V. (2019). Sport entrepreneurial ecosystems and knowledge spillovers. Knowledge Management Research and Practice, 1-10.

Ratten, V., \& Babiak, K. (2010). The role of social responsibility, philanthropy and entrepreneurship in the sport industry. Journal of Management and Organization, 16(4), 482-7. 